\title{
Frequency of electrolyte imbalance associated with cisplatin in oral cancer patients; a tertiary care experience from Pakistan
}

\author{
Kashif Gulzar* ${ }^{\mathbb{D}}$, Maseer Ahmed, Abdul Manan Junejo \\ Nephrology Unit, Jinnah Postgraduate Medical College, Karachi, Pakistan
}

\section{A R T I C L E I N F O}

Article Type:

Original

\section{Article History:}

Received: 9 May 2018

Accepted: 2 July 2018

ePublished: 28 July 2018

\section{Keywords:}

Chemotherapy

Cisplatin

Hyponatremia

Hypokalemia

Hypocalcemia

Hypomagnesemia

\begin{abstract}
A B S T R A C T
Introduction: Electrolyte imbalance associated with cisplatin is quite prevalent, and increase morbidity in cancer patients.

Objectives: To determine the frequency of electrolyte imbalance associated with cisplatin in oral cancer patients.

Patients and Methods: Oral cancer patients of more than 16 years of age, who received cisplatin-based cancer chemotherapy, were monitored for electrolyte imbalance ( $\mathrm{Na}, \mathrm{K}, \mathrm{Ca}$ and $\mathrm{Mg}$ ). Patients who were as the known cases of kidney disease (acute or chronic) or those having electrolyte imbalance prior to start of chemotherapy were excluded. Primary outcome was to determine electrolyte imbalance.

Results: Among 98 patients, 90 patients developed electrolyte imbalance to cisplatin chemotherapy. The observed electrolyte imbalance included hyponatremia, hypokalemia, hypomagnesemia and hypocalcaemia. Hypokalemia is found to be the most common electrolyte to be affected in the patients (91.8\%), whereas hypocalcemia in $88.7 \%$, hypomagnesemia in $67.34 \%$ is also observed. Mild hyponatremia is also observed less frequently in $67 \%$ of patients. Conclusion: Cisplatin-based chemotherapy has a high potential to cause electrolyte imbalance. Most of the abnormalities were of milder nature and not associated with symptoms. The common electrolyte abnormalities such as hypokalemia, hypocalcemia and hypomagnesemia were statistically significant, but hyponatremia was not statistically significant.
\end{abstract}

\footnotetext{
Implication for health policy/practice/research/medical education:

Chemotherapeutics, on the one hand, has changed the concept of cancer treatment and on other hand causes various effects which increases morbidity of patients. Cisplatin is effective in treating oral cancers but associated electrolyte imbalance is the main concern.

Please cite this paper as: Gulzar K, Ahmed M, Junejo AM. Frequency of electrolyte imbalance associated with cisplatin in oral cancer patients; a tertiary care experience from Pakistan. J Nephropharmacol. 2018;7(2):126-130.
}

\section{Introduction}

Platinum based chemotherapeutics like cisplatin, carboplatin, oxaliplatin, satraplatin, and picoplatin are in use for treating the solid organ malignancies since 1978 (1). Platinum based chemotherapeutics induces apoptosis by cross linking DNA. Cisplatin, (cisplatinum, or cis-diamminedichloroplatinum) is the first class of platinum based chemotherapeutics, a known therapeutic option in multi-technique treatment of oral cancers (24). Oral cavity and oropharynx malignancies are third most prevalent after stomach and cervical cancers, constitute around 2 to $5 \%$ of head and neck cancers (5). Approximately, 450000 new case of oral cancers reported in 2017 worldwide (6). Bhurgri et al (Pakistan) reported 4.1 and 4 oral cancer cases per 100000 population per year in males and females respectively (7).

Platinum based chemotherapeutics have common side effects such as nephrotoxicity, neurotoxicity, ototoxicity, nausea, vomiting and electrolyte imbalance and myelosuppression principally like thrombocytopenia (1). Side effects profile of carboplatin is better than cisplatin especially in children (8). Early reports indicate that nephrotoxicity might occur in 50 to $75 \%$ of patients receiving cisplatin (9). However, reversible nephrotoxicity was generally noted between doses of 50 and $75 \mathrm{mg} /$ $\mathrm{m}^{2}$, while doses more than $100 \mathrm{mg} / \mathrm{m}^{2}$ were frequently followed by acute renal failure in $47 \%$ of cases (10).

Electrolyte imbalance is also quite common in cisplatin patients such as hypomagnesaemia (60\%-90\%), hypocalcaemia (70\%-90\%), hypokalemia (70\%-95\%) and 
hyponatremia (60\%-80\%) (9). Injury to proximal tubules by cisplatin leads to decrease absorption and persistent excretion of magnesium, potassium and calcium (11). Hence, the deranged renal function or electrolyte imbalance associated along with cisplatin therapy increases the morbidity and mortality of patients.

\section{Objectives}

Nephrotoxicity and electrolyte imbalance associated with cisplatin has a significant impact on patient's morbidity. Thus, its frequency determination in our population is important to reduce the burden of nephrotoxicity. This study aimed to determine the frequency of electrolyte imbalance associated with cisplatin in oral cancer patients.

\section{Patients and Methods}

\section{Study population}

This prospective study was conducted in oncology ward of Jinnah Postgraduate Medical Centre, over a period of 3 months (November 1, 2016 to May 7, 2017). Oral cancer patients of either gender, more than 16 years of age and normal electrolytes before cisplatin therapy were included, whereas patients having derange renal function or abnormal electrolytes before cisplatin were excluded.

Those who fulfil the inclusion criteria were enrolled and informed consent was taken. All the demographic details (name, gender, age, occupation and education), clinical data (diagnosis) and therapeutic data (name of the drug, dose, route, frequency and duration of therapy) were collected from patients' records. Blood count, serum creatinine and blood urea nitrogen (BUN), serum electrolytes, urine electrolytes and albumin, analysis was conducted using VITROS Ortho-Clinical Diagnostics kits.

Before and after the completion of three cisplatin-based chemotherapy cycles, we assessed serum electrolytes, creatinine, BUN, urine protein, urine sodium, potassium and $\mathrm{pH}$. Chemotherapy was given weekly, whereas concurrently radiotherapy with linear accelerator (6MV $\mathrm{X}$-rays) in conventional fraction (1.8 Gy/fraction) was given once a day, 5 fractions per week using shrinking field technique. Each cycle of cisplatin $100 \mathrm{mg} / \mathrm{m}^{2}$ at day 1,07 and 22, after premedication with ondansetron 8 $\mathrm{mg} / \mathrm{IV}$ stat, ranitidine $150 \mathrm{mg} / \mathrm{IV}$, normal saline/IV 1000 $\mathrm{mL}$ before and after cisplatin therapy. The electrolyte imbalance associated with cisplatin will be assessed by measuring of pre-cisplatin and post-cisplatin cycle, of parameters such as sodium, potassium, calcium and magnesium.

\section{Ethical considerations}

This research was performed following the Declaration of Helsinki principles. Informed written consent was obtained from each patient. All information about individuals was coded and kept confidential. This study was approved by the institutional ethical committee and research oversight committee, Jinnah Post Graduate Medical Center, Karachi, Pakistan.

\section{Statistical analysis}

All the analysis will be conducted on Statistical Package for Social Sciences (SPSS) (Release 10.0, standard version). Mean \pm standard deviation (SD) will be calculated for continuous variables like age, change in serum potassium, calcium, magnesium, sodium while, frequency distribution will be calculated for categorical variables like gender hypokalemia, hypocalcemia, hyponatremia and hypomagnesemia. Effect modifier will be controlled by stratification of age, controlling co-morbid conditions (diabetes and hypertension), weight, stage of the disease and premedication before cisplatin chemotherapy (IV fluids, antiemetics and antacids), using chi-square test. Accordingly $P$ values equal to or less than 0.05 will be considered as statistically significant.

\section{Results}

A total of 98 patients were enrolled to the study, with mean age of $44.88 \pm 17.28$ years [ $<40$ years ( 33 patients, $33.67 \%$ ), 40-60 years ( 57 patients, $58.16 \%$ ), $>60$ years (08 patients, $08.1 \%)$ ]. In enrolled patients, number of male (68 patients, $69.38 \%$ ) were more than female (38, patients $30.61 \%$ ). The most common histological lesion is squamous cell carcinoma in 82 patients (83.67\%) and $78 \%$ in stage III followed by $14 \%$ in stage II in TNM staging. Most common site of lesions is mucosa of cheek 33 (33.67\%), followed by tongue and floor of mouth. Tobacco consumption is observed in $87(88.77 \%)$ of patients (see Table 1$)$.

\section{Effects of cisplatin on serum electrolytes}

Hypokalemia is observed in 90 (91.83\%), percent decrease

Table 1. Patients characteristics $(n=98)$

\begin{tabular}{lc}
\hline Variable & No. (\%) \\
\hline Age $(\mathrm{y})$ & $33(33.67)$ \\
$<40$ & $57(58.16)$ \\
$40-60$ & $08(08.1)$ \\
$>60$ & \\
Gender & $60(61.2)$ \\
Male & $38(38.8)$ \\
Female & \\
Oral cancer (histological type) & $82(83.67)$ \\
Squamous cell cancers & $12(12.24)$ \\
Verucous carcinoma & $4(4.08)$ \\
Others & \\
Site of lesion & $33(33.67)$ \\
Cheek & $20(20.40)$ \\
Tongue & $20(20.40)$ \\
Floor of mouth & $16(16.32)$ \\
Lips & $09(9.18)$ \\
Hard palate & $87(88.77)$ \\
Tobacco consumption &
\end{tabular}


in potassium is $-9.4 \%$, and is more common in male than female, whereas hypocalcemia is reported in $87(88.77 \%)$ of patients while percent decrease is $-6.66 \%$ (hypocalcemia is more common in male). Hypomagnesemia is reported in $66(67.34 \%)$ of patients (percent change is $-7.18 \%$ ), and hyponatremia was observed in 66 of cases $(67.34 \%)$, while percent decrease was $-3.35 \%$ (both are frequent in females than males) (Tables 2, 3 and 4).

Stratification of age shows hypokalemia and hypocalcemia are more frequent among young and middle age group than older patients, whereas hyponatremia is frequent in older age patients and hypomagnesemia more frequent in younger patients (Table 5).

Stratification according to type of oral cancer revealed that in squamous cell carcinoma, the most frequent electrolyte abnormality associated with cisplatin was

Table 2. Frequency of electrolyte imbalance

\begin{tabular}{lcc}
\hline Electrolyte imbalance & $\begin{array}{c}\text { Yes } \\
\text { No. (\%) }\end{array}$ & $\begin{array}{c}\text { No } \\
\text { No. (\%) }\end{array}$ \\
\hline Hypokalemia & $90(91.83)$ & $8(8.17)$ \\
Hypocalcemia & $87(88.77)$ & $11(11.23)$ \\
Hypomagnesemia & $66(67.34)$ & $32(32.66)$ \\
Hyponatremia & $66(67.34)$ & $32(67.34)$ \\
\hline
\end{tabular}

hypokalemia (93.9\%) and least common is hyponatremia (68.2\%), whereas hypocalcemia (91.6\%) is most common and hypomagnesemia (16.6\%) is least common cisplatin associated electrolyte abnormality in verrucous type (Table 6).

Stratification according to staging of oral cancer is given in Table 7. Table 7 shows that in stage III, hypokalemia (94.6\%) and hypomagnesemia $(80.35 \%)$ are more frequent. In stage II, hypocalcemia (93.3\%) is more frequent, whereas in stage IV, hyponatremia is the least frequent and the rest three are equally frequent (83.3\%).

\section{Discussion}

This study was conducted to detect electrolyte imbalance after cisplatin cycles, thereby allowing supplementation of deficient electrolytes without disrupting the chemotherapy cycles.

Cisplatin is known for its effectiveness in the treatment of oral cancers, however, nephrotoxicity associated with cisplatin is reported for years. The exact mechanism has not been fully understood. It may increase membrane fragility and deplete intracellular glutathione while interacting with sulfhydryl compound. Additionally, cisplatin can induce apoptosis and necrosis of kidney cells in a dose dependent fashion. Cisplatin associated nephrotoxicity

Table 3. Change in electrolytes pre-cisplatin and post-cisplatin therapy

\begin{tabular}{lccc}
\hline Serum electrolyte & Pre-cisplatin & Post-cisplatin & Decrease in electrolytes \\
\hline$P(m E q / d L) ~(n=90)$ & $4.02 \pm 0.30$ & $3.13 \pm 0.31$ & $0.63 \pm 0.15$ \\
$\mathrm{Ca}(\mathrm{mg} / \mathrm{dL})(\mathrm{n}=87)$ & $9.12 \pm 0.46$ & $8.02 \pm 0.32$ & $0.76 \pm 0.32$ \\
$\mathrm{Mg}(\mathrm{mg} / \mathrm{dL})(\mathrm{n}=66)$ & $2.26 \pm 0.34$ & $1.39 \pm 0.28$ & $0.45 \pm 0.12$ \\
$\mathrm{Na}(\mathrm{mEq} / \mathrm{dL})(\mathrm{n}=66)$ & $141.6 \pm 4.9$ & $130.2 \pm 3.1$ & 0.03 \\
\hline
\end{tabular}

Table 4. Stratification of electrolyte imbalance as per gender

\begin{tabular}{|c|c|c|c|c|c|}
\hline \multirow[b]{2}{*}{ Electrolyte Imbalance } & \multicolumn{2}{|c|}{ Male $(n=60)$} & \multicolumn{2}{|c|}{ Female $(n=38)$} & \multirow[b]{2}{*}{$P$ value } \\
\hline & $\begin{array}{c}\text { Yes } \\
\text { No. (\%) }\end{array}$ & $\begin{array}{c}\text { No } \\
\text { No. (\%) }\end{array}$ & $\begin{array}{c}\text { Yes } \\
\text { No. (\%) }\end{array}$ & $\begin{array}{c}\text { No } \\
\text { No. (\%) }\end{array}$ & \\
\hline Hypokalemia & $57(91.6)$ & $03(08.4)$ & 33 (78.9) & $05(21.1)$ & 0.001 \\
\hline Hypocalcemia & $53(88.3)$ & $07(11.7)$ & $34(89.4)$ & $04(10.6)$ & 0.001 \\
\hline Hypomagnesemia & $36(60)$ & $24(40)$ & $25(65.8)$ & $13(34.2)$ & 0.025 \\
\hline Hyponatremia & $38(63.3)$ & $22(36.7)$ & $28(73.7)$ & $10(26.3)$ & 0.01 \\
\hline
\end{tabular}

${ }^{a}$ Chi square test.

Table 5. Stratification of electrolyte imbalance as per age

\begin{tabular}{|c|c|c|c|c|c|c|c|}
\hline \multirow[b]{2}{*}{ Electrolyte Imbalance } & \multicolumn{2}{|c|}{$<40$ years $(n=33)$} & \multicolumn{2}{|c|}{$40-60$ years $(n=57)$} & \multicolumn{2}{|c|}{$>60$ years $(n=8)$} & \multirow[b]{2}{*}{$P$ value $^{a}$} \\
\hline & $\begin{array}{c}\text { Yes } \\
\text { No. (\%) } \\
\end{array}$ & $\begin{array}{c}\text { No } \\
\text { No. (\%) }\end{array}$ & $\begin{array}{c}\text { Yes } \\
\text { No. (\%) } \\
\end{array}$ & $\begin{array}{c}\text { No } \\
\text { No. (\%) }\end{array}$ & $\begin{array}{c}\text { Yes } \\
\text { No. (\%) }\end{array}$ & $\begin{array}{c}\text { No } \\
\text { No. (\%) } \\
\end{array}$ & \\
\hline Hypokalemia & $29(87.8)$ & $4(12.2)$ & $55(96.4)$ & $2(03.6)$ & $6(75)$ & $2(25)$ & 0.001 \\
\hline Hypocalcemia & $27(81.8)$ & $6(18.2)$ & $53(92.8)$ & $4(07.2)$ & 7 (87.5) & $1(12.5)$ & 0.005 \\
\hline Hypomagnesemia & $24(72.7)$ & $9(27.3)$ & $37(64.9)$ & $20(35.1)$ & $5(62.5)$ & $3(37.5)$ & 0.001 \\
\hline Hyponatremia & $19(57.6)$ & $14(42.4)$ & $41(71.2)$ & $16(28.8)$ & $6(75)$ & $2(25)$ & 0.1 \\
\hline
\end{tabular}

${ }^{\mathrm{a}}$ Chi square test. 
Table 6. Stratification of electrolyte imbalance as per type of carcinoma

\begin{tabular}{|c|c|c|c|c|c|}
\hline \multirow[b]{2}{*}{ Electrolyte Imbalance } & \multicolumn{2}{|c|}{ Squamous carcinoma $(n=82)$} & \multicolumn{2}{|c|}{ Verrucous carcinoma $(n=12)$} & \multirow[b]{2}{*}{$P$ value $^{a}$} \\
\hline & $\begin{array}{c}\text { Yes } \\
\text { No. (\%) }\end{array}$ & $\begin{array}{c}\text { No } \\
\text { No. (\%) }\end{array}$ & $\begin{array}{c}\text { Yes } \\
\text { No. (\%) }\end{array}$ & $\begin{array}{c}\text { No } \\
\text { No. (\%) }\end{array}$ & \\
\hline Hypokalemia & 77 (93.9) & $05(06.1)$ & $09(75)$ & $03(25)$ & 0.001 \\
\hline Hypocalcemia & $72(87.8)$ & $10(12.2)$ & $11(91.6)$ & $01(08.4)$ & 0.004 \\
\hline Hypomagnesemia & $62(75.6)$ & $20(24.4)$ & $02(16.6)$ & $10(80.4)$ & 0.07 \\
\hline Hyponatremia & $56(68.2)$ & $26(31.8)$ & $07(58.3)$ & $05(41.7)$ & 0.1 \\
\hline
\end{tabular}

${ }^{\text {a }}$ Chi square test.

Table 7. Stratification of electrolyte imbalance as per stage of carcinoma

\begin{tabular}{|c|c|c|c|c|c|c|c|}
\hline \multirow[b]{2}{*}{ Electrolyte imbalance } & \multicolumn{2}{|c|}{ Stage II $(n=30)$} & \multicolumn{2}{|c|}{ Stage III $(n=56)$} & \multicolumn{2}{|c|}{ Stage IV $(n=12)$} & \multirow[b]{2}{*}{$P$ value $^{a}$} \\
\hline & $\begin{array}{c}\text { Yes } \\
\text { No. (\%) }\end{array}$ & $\begin{array}{c}\text { No } \\
\text { No. (\%) }\end{array}$ & $\begin{array}{c}\text { Yes } \\
\text { No. (\%) }\end{array}$ & $\begin{array}{c}\text { No } \\
\text { No. (\%) }\end{array}$ & $\begin{array}{c}\text { Yes } \\
\text { No. (\%) }\end{array}$ & $\begin{array}{c}\text { No } \\
\text { No. (\%) }\end{array}$ & \\
\hline Hypokalemia & $27(90)$ & $3(10)$ & $53(94.6)$ & $3(5.4)$ & $10(83.3)$ & $2(16.7)$ & 0.001 \\
\hline Hypocalcemia & $28(93.3)$ & $2(6.7)$ & $49(87.5)$ & $7(12.5)$ & $10(83.3)$ & $2(16.7)$ & 0.001 \\
\hline Hypomagnesemia & $14(46.6)$ & $16(53.4)$ & $45(80.35)$ & $11(19.65)$ & $7(58.3)$ & $5(41.7)$ & 0.4 \\
\hline Hyponatremia & $26(86.6)$ & $4(13.4)$ & $30(53.5)$ & $26(46.5)$ & $10(83.3)$ & $2(16.7)$ & 0.1 \\
\hline
\end{tabular}

${ }^{a}$ Chi square test.

manifest clinically as rise in BUN, creatinine, disturbance in electrolytes and acute renal failure. Furthermore, cisplatin associated nephrotoxicity histologically manifests with acute focal tubular necrosis, convoluted tubule and collecting duct dilatation. The present study suggests that these changes must be reversible. At present, to avoid renal impairment and electrolyte imbalance, hydration and forced dieresis are administered as prophylaxis (12).

In the present study, we observed hypokalemia (91.83\%), hypocalcemia (87.75\%), hypomagnesemia (67.34\%) and hyponatremia $(67.34 \%)$ after three cycles of cisplatin therapy (Table 2). In our study population, hypokalemia is the commonest electrolyte abnormality, observed in 90 patients $(91.83 \%, P=0.002)$. A significant decrease in potassium level was observed in males, especially in younger and middle age groups (Tables 3 and 4), whereas Arunkumar et al (13) observed in 92\% of their patients. Increased renal absorption capacity, in response to decreased absorption of intestinal potassium is a possible explanation behind it. Furthermore, magnesium and potassium are subjected to change in intestinal absorption and renal excretion with each cisplatin treatment (14). Previous studies have suggested that cisplatin is known to produce hypokalemic paralysis (15) however, we had not paralysis in our study population.

Hypocalcemia is also quite common side effect of cisplatin chemotherapy. In our study population, 87 patients suffered from hypocalcemia $(88.77 \%, P=0.03$; Table 2), whereas Arunkumar et al (13) found in $80 \%$ of their study population. Furthermore, in our observation both genders are significantly affected. Additionally hypocalcemia affects younger patients more as compared to others (Tables 3 and 4). The possible mechanism behind this complication is excessive urinary loss of calcium in urine, decreased renal tubular reabsorption of calcium due to tubular damage, due to low tissue response to parathormone, and low serum magnesium levels (16). Electrolyte monitoring and continuous oral calcium substitution is advised for patients undergoing cisplatin therapy.

Hypomagnesemia is a well-known side effect of cisplatin treatment. In our study, $67.34 \%$ of patients developed this complication. Female suffer more as compared to male (66, $P=0.003$; Tables 2 and 5), In contrast, Markman et al (17) reported the incidence of cisplatin-induced hypomagnesemia in $89 \%$ of ovarian cancer but their sample size was small. Direct injury to renal magnesium reabsorption in ascending loop of Henle, and distal tubule, is the possible mechanism behind the cisplatin-induced hypomagnesemia (18).

Hyponatremia is not uncommon in patients on cisplatin chemotherapy. Renal salt wasting and syndrome of inappropriate antidiuretic hormone are possible mechanisms behind cisplatin-induced hyponatremia (19). Cisplatin-induced hyponatremia was observed in $67.34 \%$ (Tables 2 and 5) of our study population. Cisplatin-induced hyponatremia was more common in females and patients with older age group (Tables 3 and 4). Hamdi et al (18) reported 69\% incidence of cisplatininduced hyponatremia, on contrary Arunkumar et al (13) reported an increase in serum sodium level. They concluded that, opined that this may be due to infusing normal saline before cisplatin chemotherapy. Frequency and severity of cisplatin nephrotoxicity may be reduced by slow intravenous electrolyte infusions and maintaining the hydration, before, during and immediately after the administration of cisplatin

\section{Conclusion}

Our study concluded that electrolyte abnormalities are 
hypokalemia, hypocalcemia, hypomagnesemia and hyponatremia, which were observed after three cycles of cisplatin. Hypokalemia, hypocalcemia, hypomagnesemia were statistically significant, but hyponatremia was not statistically significant.

\section{Limitations of the study}

One of the limitations of the study is the number of patients attending chemotherapy clinic. Larger studies in this regard are necessary.

\section{Authors' contribution}

KG participated in the data collection and main draft. MA and AMJ contributed to intellectual input and critical revision. All authors read and signed the final paper.

\section{Conflicts of interest}

The authors declare no conflict of interest.

\section{Ethical considerations}

Ethical issues (including plagiarism, data fabrication, double publication) have been completely observed by the authors.

\section{Funding/Support}

This study was conducted with collaboration of department of nephrology and oncology, supported by Jinnah Postgraduate Medical Centre.

\section{References}

1. Lloyd K. The resurgence of platinum based cancer chemotherapy. Nat Rev Cancer. 2007;7:573-84. doi: $10.1038 /$ nrc2167.

2. Kovács AF, Schiemann M, Turowski B. Combined modality treatment of oral and oropharyngeal cancer including neoadjuvant intra-arterial cisplatin and radical surgery followed by current radiation and chemotherapy with weekly docetaxel: three-year results of a pilot study. Craniomaxillofac Surg. 2002; 30:112-20.

3. Robbins KT, Storniolo AM, Kerber C. Rapid super selective high-dose cisplatin infusion for advanced head and neck malignancies. J Clin Oncol. 1992; 14:364-71.

4. Robbins KT, Storniolo AM, Kerber C. Phase I study of highly selective supradose cisplatin infusions for advances head and neck cancer. J Clin Oncol. 1994; 12:2113-20.

5. Weber AL, Romo L, Hashmi S. Malignant tumors of the oral cavity and oropharynx: clinical, pathologic, and radiologic evaluation. Neuroimaging Clin N Am. 2003; 3:443-64.

6. Cancer Foundation. Oral Cancer Facts. Cancer Foundation; 2018. [updated 5th June 2018]. Available from: https:// oralcancerfoundation.org/facts/.

7. Bhurgri Y, Rahim A, Bhutto K, Bhurgri A, Pinjani PK, Usman A. Incidence of carcinoma of the oral cavity in Karachi--district south. J Pak Med Assoc. 1998; 48:321-5.

8. Asim M, Usaid A, Sikandar H. Platinum compound induced Nephrotoxicity and ototoxicity in childhood cancers. Pak Paed J. 2011:35:70-5.

9. Lameire N, Van Biesen W, Vanholder R. Electrolyte disturbances and Acute kidney injury in patients with cancer. Semin Nephrol. 2010;30:534-47.

10. Ries F, Klastersky J. Nephrotoxicity induced by cancer chemotherapy with special emphasis on cisplatin toxicity. Am J Kidney Dis. 1986; 8:368-79.

11. Zekri JM, Cheah NL, Evans L, Hancock B. Serum potassium, calcium and magnesium in patients receiving ESHAP chemotherapy for relapsed lymphomas. J R Coll Physicians Edinb. 2009;39(4):301-6. doi: 10.4997/JRCPE.2009.403.

12. Bodnar L, Wcislo G, Gasowska-Bodnar A, Synowiec A, Szarlej-Wcisło K, Szczylik C. Renal protection with magnesium subcarbonate and magnesium sulphate in patients with epithelial ovarian cancer after cisplatin and paclitaxel chemotherapy: a randomised phase II study. Eur J Cancer 2008; 44:2608-14. doi: 10.1016/j.ejca.2008.08.005.

13. Arunkumar PA, Viswanatha GL, Radheshyam N, Mukund $\mathrm{H}$, Belliyappa MS. Science behind cisplatin induced nephrotoxicity in humans: a Clinical study. Asian Pac J Trop Biomed. 2012;2:640-644. doi: 10.1016/S22211691(12)60112-9.

14. Yao X, Panichpisal K, Kurtzman N, Nugent K. Cisplatin nephrotoxicity: a review. Am J Med Sci 2007;334:116-124.

15. Surendiran A, Balamurugan N, Gunaseelan K, Akhtar S, Reddy KS, Adithan C. Adverse drug reaction profile of Cisplatin-based chemotherapy regimen in a tertiary care hospital in India: an evaluative study. Indian J Pharmacol. 2010; 42:40-43.

16. Goren MP. Cisplatin nephrotoxicity affects magnesium and calcium metabolism. Med Pediatr Oncol. 2003;41:186-189.

17. Markman M, Rothman R, Reichman B, Hakes T, Jewis JL Jr, Rubin S, et al. Persistent hypomagnesemia following cisplatin chemotherapy in patients with ovarian cancer. J Cancer Res Clin Oncol. 1991;117:89-90.

18. Anvari K, Sielanian Toussi M, Mirsadraee M. Evaluation of intravenous magnesium supplementation as prophylaxis for cisplatin-induced hypomagnesemia. Middle East J Cancer 2010; 1:109-114.

19. Hamdi T, Latta S, Jallad B, Kheir F, Alhosaini MN, Patel A. Cisplatin-induced renal salt wasting syndrome. South Med J. 2010; 103:793-799.

Copyright $\odot 2018$ The Author(s); Published by Society of Diabetic Nephropathy Prevention. This is an open-access article distributed under the terms of the Creative Commons Attribution License (http://creativecommons.org/licenses/by/4.0), which permits unrestricted use, distribution, and reproduction in any medium, provided the original work is properly cited. 